\title{
Attraction of the Japanese pine sawyer, Monochamus alternatus, to volatiles from stressed host in China
}

\author{
Jianting FAN ${ }^{\mathrm{a}, \mathrm{b}}$, Jianghua SUN ${ }^{\mathrm{a} *}, \mathrm{Jin}_{\mathrm{SHI}}^{\mathrm{c}}$ \\ a State Key Laboratory of Integrated Management of Pest Insects and Rodents, Institute of Zoology, Chinese Academy of Sciences, \\ Beijing 100080, China \\ ${ }^{\mathrm{b}}$ Graduate School of the Chinese Academy of Sciences, Beijing 100080, China \\ ${ }^{\mathrm{c}}$ Forest Pest Control Station of Anhui Province, Hefei 230031, China
}

(Received 15 July 2005; accepted 26 April 2006)

\begin{abstract}
Ovipositing female Japanese sawyer beetles, Monochamus alternatus, prefer stressed Pinus massoniana over healthy trees. Host discrimination by M. alternatus suggests that changes in the chemical composition of pines may mediate the host preference of beetles. Volatile compounds from stressed and healthy pine stems were collected using absorbent trap collection method. Significant differences in absolute terpene quantities between stressed and healthy pines occurred for 7 of 10 terpenes. Field trials demonstrated that four terpenes identified from host pines were attractive to $M$. alternatus with (+)- $\alpha$-pinene as the most attractive compound to M. alternatus. Ethanol appeared to be an important synergistic compound causing significant increase in attraction.
\end{abstract}

Monochamus alternatus / pine volatile / trapping / terpene / attractant

Résumé - Des composés émis par les arbres-hôtes stressés sont attractifs pour le cérambycidé Monochamus alternatus. Les femelles du cérambycidé Monochamus alternatus préfèrent pondre sur les arbres stressés que sur les arbres sains de Pinus massoniana. Cette discrimination dans le choix de l'hôte par l'insecte pourrait être reliée à des modifications intervenues dans la composition chimique des pins. Les composés volatils émis par des pins stressés et sains ont été collectés en utilisant une méthode de piégeage sur résine adsorbante. La quantité absolue de 7 terpènes sur les 10 analysés diffère significativement entre pins stressés et sains. Des essais sur le terrain ont montrés que 4 de ces terpènes sont attractifs pour M. Alternatus. l'(+)- $\alpha$-pinène étant le compose le plus attractif. L'éthanol semble être un composé synergique induisant une augmentation significative de l'attraction.

Monochamus alternatus / composés / volatil des pins / piégeage / terpènes / attractif

\section{INTRODUCTION}

The Japanese pine sawyer beetle, Monochamus alternatus Hope (Coleoptera: Cerambycidae), is the most important vector for the transmission of the pine wood nematode, Bursaphelenchus xylophilus (Steiner and Buhrer) Nickle (Nematoda: Aphelenchoididae), in Japan and China [7, 13, 29, 30]. The direct economic losses caused by the pine wood nematode in China are estimated at approximately 2.5 billion RMB with indirect economic losses exceeding 25 billion RMB [29]. $M$. alternatus has been recorded on more than 15 species of $\mathrm{Pi}$ nus, plus several species of Abies, Cedrus, Picea, and Larix [29]. Losses of Masson pine, Pinus massoniana, an indigenous species found in 19 southern provinces of China, has counted for $40-50 \%$ of tree mortality in southern China [7, 32].

Location of suitable host plants by herbivorous insects upon which to feed or oviposit may be mediated by plant volatile semiochemicals $[3,9,20]$. Some insects can identify unsuitable hosts by detecting ratios of common plant components

\footnotetext{
*Corresponding author: sunjh@ioz.ac.cn
}

not normally encountered in suitable hosts $[5,25,26]$. The importance of terpenes present in coniferous trees as oviposition stimulants or feeding deterrents to bark and wood boring insects has been well established [1, 12, 14, 21]. Terpenes emitted from or contained in stressed or injured pines may influence host selection during the oviposition period [27]. Ikeda et al. [11] collected the volatiles from the felled $P$. densiflora by means of the cold trap method and identified 11 monoterpenes. In field trials, they demonstrated that the addition of ethanol significantly increased catches of $M$. alternatus to terpene baited traps.

Observations indicated that ovipositing female $M$. alternatus prefer stressed to healthy $P$. massoniana, so host discrimination by $M$. alternatus may be related to changes in the chemical composition of pines following injury or stress conditions. The objective of this study was to investigate the mechanism underlying host discrimination by $M$. alternatus on Masson pine in China. Specifically, we attempted to isolate and compare terpenes emitted by injured, stressed trees versus healthy ones. Once the key compounds were identified, 
trapping experiments were conducted to assess the attractiveness individually and in various ratios.

\section{MATERIALS AND METHODS}

\subsection{Pine material}

The study was conducted at Jingtingshan Forestry Centre, Xuancheng, Anhui, in 2004 using 14- to 16-year old Masson pines. Stressed trees were created by cutting three wounds on the stem in different directions with an axe, then injecting wounds with $5 \mathrm{~mL}$ of $5 \%$ aqueous solution of purified paraquat dichloride.

\subsection{Volatiles collection and analysis}

Volatiles were collected from the stems of the test trees using an absorbent trap collection method one week post-treatment. Polyvinyl plastic bags (Reynolds, Richmond, VA, USA) were tightly bound on the stems. Each bag was attached to glass tubing $(7 \mathrm{~cm} \times 0.5 \mathrm{~cm}-\mathrm{ID})$ containing $0.5 \mathrm{~cm}$ of XAD-2 (Amberlite, Philadelphia, PA, USA) and sealed at the end with glass wool (Supelco, Bellefonte, PA, USA). The tubing was then connected to the air inlet of a QC-1 gas sampler (Beijing Municipal Institute of Labour Protection, Beijing, China). A second tubing $(7 \mathrm{~cm} \times 1 \mathrm{~cm}$-ID) attached to the bags contained $5 \mathrm{~cm}$ of activated charcoal was connected to the air outlet of the QC-1 gas sampler allowing purified air flow into the bags. A constant airflow of $1.5 \mathrm{~L} / \mathrm{min}$ was maintained by a flowmeter. All devices were connected with silica gel tubing. Plant volatiles were sampled for 5 h (10:0015:00) with five replicates per treatment. Volatiles of each sample were separately eluted from the Supelco pack with $500 \mu \mathrm{L}$ hexane containing $50 \mathrm{ng} / \mu \mathrm{L}$ dodecane. The dodecane served as a qualitative internal standard, as it is not present in pine volatiles and is easily separated from the naturally present terpenes. Collected samples were stored at $-5{ }^{\circ} \mathrm{C}$ until needed.

Collected samples were diluted by a factor of 20 with analysisgrade pure hexane and subsequently analyzed by gas chromatograph mass spectrometry (Agilent 6890N-5973N GC/MSD, Agilent Technologies, Palo Alto, CA, USA). The carrier gas was helium $(99.999 \%)$ at a flow rate of $1 \mathrm{ml} / \mathrm{min}$. A $60 \mathrm{~m}$ (length) $\times 0.25 \mathrm{~mm}$ (ID) $\times 0.25 \mu \mathrm{m}$ (film) capillary column (DB-5MS, J\&W Scientific, Folsom, CA, USA) was employed with $2 \mu \mathrm{L}$ sample injections done in 50:1 split ratio. The temperature program was $50^{\circ} \mathrm{C}$ for $2 \mathrm{~min}$, then increased to $200{ }^{\circ} \mathrm{C}$ at a rate of $5{ }^{\circ} \mathrm{C} / \mathrm{min}$, and finally increased and maintained at $220^{\circ} \mathrm{C}$ for $5 \mathrm{~min}$. The flame ionization detector temperature was $300{ }^{\circ} \mathrm{C}$, with an injector temperature was $250{ }^{\circ} \mathrm{C}$. The mass spectrometer was operated in the $70 \mathrm{eV}$ ionisation mode (EI). Spectra were continuously scanned in a mass range from 30-300 amu.

\subsection{Field trap experiment}

The field trapping experiments were conducted in 2004 in the Jingtingshan Forestry Centre of Xuancheng, Anhui province. The attractive effects of the monoterpenes $(+)-\alpha$-pinene, $(-)-\beta$-pinene, and $(+)-3$-carene were tested, as they were detected in the analyses of host volatiles. Terpinolene was included as it previously had been used in field trials to assess attraction of M. alternatus [11]. Each monoterpene was tested individually. An orthogonal design method also was employed to compare the attraction of different ratios of a blend of the four monoterpenes [15]. This design allows four factors (the monoterpenes) at three concentrations to be tested simultaneously, providing an easy assessment of optimal protocol conditions. Ethanol also was tested as a potential synergist. The treatments and ratios employed in the trapping experiments for M. alternatus are presented in Table II.

A cross vanes type trap was used for beetle collection [28]. The traps were suspended from a stick attached horizontally to two adjacent trees. The collection cups ca. $80 \mathrm{~cm}$ above ground level, the height at which $M$. alternatus attacks trees. The elution device for the chemicals was a closed $18 \mathrm{~mL}$ polyethylene release bottles, manufactured at the Hongzhi Plastic Plant in Taiyuan, Shanxi Province. Each bottle contained $15 \mathrm{~mL}$ of the specific monoterpene or semiochemical blend. The release rate of the lures was $300 \mu \mathrm{L} / \mathrm{d}$, with replacement every 4 weeks [23].

Five replicates each of 15 treatments were randomly deployed at the Centre with a spacing of $20 \mathrm{~m}$ between traps. Ten traps with an empty release bottle served as controls. The experiment was established 1 June 2004, and beetles were collected from traps every 7 days through 1 September 2004. This time interval corresponds with the oviposition period of the beetles [6]. All M. alternatus adults captured in each trap on each date were counted and recorded. Female were dissected and the number of eggs counted.

\subsection{Statistical analysis}

Quantitative compositions of volatiles were calculated from peak areas using dodecane as the internal standard. The identification of the chemical constituents of each sample was based on a comparison of their retention times (Rt) and mass spectra with those obtained from the standard compounds and from the NIST Mass Spectral library. Data analyses were carried out using statistical software SPSS 11.0 for Windows [22]. Differences in absolute contents of volatile compounds between healthy and stressed pines were compared by Paired-Samples T Test. Differences of beetles attracted by different treatments were analyzed by One-Way ANOVA. Means were compared with Bonferroni multiple-comparison test. The optimal combination of the four compounds was analyzed by Univariate of General Linear Mode [31].

\section{RESULTS}

\subsection{Volatiles analysis}

There were significant differences between stressed and healthy trees for 7 of the 10 terpenes detected (Tab. I). Camphene, $\beta$-phellandrene, $\alpha$-copaene, longifolene and $\beta$ caryophyllene were not detected in healthy trees. Moreover, $\alpha$-pinene, $\beta$-pinene and D-limonene were more abundant in stressed trees than in healthy ones. Approximately $81 \%$ of the total volatiles emitted by stressed trees was $\alpha$-pinene, and the level of $\alpha$-pinene was more than 100 times higher than in healthy trees. $\beta$-Myrcene, 3 -carene, and $\alpha$-copaene were found in trace amounts and were not significantly different between stressed and healthy stems. 
Table I. The quantitative analysis between the volatiles of stressed and healthy pines.

\begin{tabular}{lllll}
\hline & & $\begin{array}{l}\text { Stressed pines } \\
(\mathrm{ng})\end{array}$ & $\begin{array}{l}\text { Healthy pines } \\
(\mathrm{ng})\end{array}$ & $P$ \\
\hline 1 & $\alpha$-pinene & $89.65 \pm 23.05 \mathrm{a}$ & $0.80 \pm 0.22 \mathrm{~b}$ & $0.031<0.05$ \\
2 & Camphene & $2.44 \pm 0.86 \mathrm{a}$ & $0 \mathrm{~b}$ & $0.038<0.05$ \\
3 & $\beta$-pinene & $5.41 \pm 1.70 \mathrm{a}$ & $0.18 \pm 0.08 \mathrm{~b}$ & $0.039<0.05$ \\
4 & $\beta$-myrcene & $1.17 \pm 0.32 \mathrm{a}$ & $0.18 \pm 0.18 \mathrm{a}$ & 0.116 \\
5 & 3-carene & $0.65 \pm 0.25 \mathrm{a}$ & $0.55 \pm 0.22 \mathrm{a}$ & 0.800 \\
6 & D-limonene & $3.75 \pm 0.79 \mathrm{a}$ & $1.05 \pm 0.35 \mathrm{~b}$ & $0.040<0.05$ \\
7 & $\beta$-phellandrene & $1.18 \pm 0.34 \mathrm{a}$ & $0 \mathrm{~b}$ & $0.043<0.05$ \\
8 & $\alpha$-copaene & $0.49 \pm 0.32 \mathrm{a}$ & $0 \mathrm{a}$ & 0.191 \\
9 & Longifolene & $3.79 \pm 1.28 \mathrm{a}$ & $0 \mathrm{~b}$ & $0.045<0.05$ \\
10 & $\beta$-caryophyllene & $0.68 \pm 0.19 \mathrm{a}$ & $0 \mathrm{~b}$ & $0.041<0.05$ \\
\hline
\end{tabular}

ab: Different letters mean terpene emission rates (Mean \pm SE, $n=5)$ are significantly different between stressed stem and healthy stem at $p=0.05$ (paired-samples $T$ test).

Table II. The catches of adult M. alternatus to monoterpene-baited traps.

\begin{tabular}{|c|c|c|c|c|}
\hline Code & Monoterpenes* & Ratio & $\begin{array}{l}\text { Mean } \pm \text { SE } \\
\text { beetles/week }\end{array}$ & $\begin{array}{l}\text { Mean } \pm \text { SE } \\
\text { eggs/female }\end{array}$ \\
\hline 1 & $(+)$ - $\alpha$-pinene & NA & $7.42 \pm 1.10 \mathrm{a}$ & $11.00 \pm 1.29 \mathrm{a}$ \\
\hline 2 & $(-)-\beta$-pinene & NA & $3.28 \pm 0.77 \mathrm{bc}$ & $10.60 \pm 1.38 \mathrm{a}$ \\
\hline 3 & $(+)$-3-carene & NA & $2.42 \pm 0.42 \mathrm{bc}$ & $10.31 \pm 1.34 \mathrm{a}$ \\
\hline 4 & Terpinolene & NA & $1.14 \pm 0.55 \mathrm{bc}$ & $10.67 \pm 1.18 \mathrm{a}$ \\
\hline 5 & (+)- $\alpha$-pinene: (-)- $\beta$-pinene: $(+)-3$-carene:terpinolene & $1: 1: 1: 1$ & $3.14 \pm 1.22 \mathrm{bc}$ & $11.29 \pm 1.32 \mathrm{a}$ \\
\hline 6 & (+)- $\alpha$-pinene: (-)- $\beta$-pinene: $(+)-3$-carene:terpinolene & $1: 2: 2: 2$ & $2.57 \pm 0.68 \mathrm{bc}$ & $10.57 \pm 1.08 \mathrm{a}$ \\
\hline 7 & (+)- $\alpha$-pinene: (-)- $\beta$-pinene: $(+)-3$-carene:terpinolene & $1: 4: 4: 4$ & $1.42 \pm 0.61 \mathrm{bc}$ & $10.42 \pm 1.11 \mathrm{a}$ \\
\hline 8 & $(+)-\alpha$-pinene: $(-)-\beta$-pinene: $(+)-3$-carene:terpinolene & $2: 1: 2: 4$ & $0.42 \pm 0.20 \mathrm{c}$ & $10.32 \pm 1.10 \mathrm{a}$ \\
\hline 9 & (+)- $\alpha$-pinene: $(-)-\beta$-pinene: $(+)-3$-carene:terpinolene & $2: 2: 4: 1$ & $2.71 \pm 0.80 \mathrm{bc}$ & $11.11 \pm 0.80 \mathrm{a}$ \\
\hline 10 & (+)- $\alpha$-pinene: (-)- $\beta$-pinene: $(+)-3$-carene:terpinolene & $2: 4: 1: 2$ & $3.85 \pm 1.99 \mathrm{~b}$ & $9.90 \pm 1.08 \mathrm{a}$ \\
\hline 11 & (+)- $\alpha$-pinene: (-)- $\beta$-pinene: $(+)-3$-carene:terpinolene & $4: 1: 4: 2$ & $1.42 \pm 0.78 \mathrm{bc}$ & $10.42 \pm 0.78 \mathrm{a}$ \\
\hline 12 & (+)- $\alpha$-pinene: (-)- $\beta$-pinene: $(+)-3$-carene:terpinolene & $4: 2: 1: 4$ & $1.14 \pm 0.50 \mathrm{bc}$ & $10.14 \pm 1.20 \mathrm{a}$ \\
\hline 13 & (+)- $\alpha$-pinene: $(-)-\beta$-pinene: $(+)-3$-carene:terpinolene & $4: 4: 2: 1$ & $2.42 \pm 0.71 \mathrm{bc}$ & $10.42 \pm 0.91 \mathrm{a}$ \\
\hline 14 & (+)- $\alpha$-pinene: (-)- $\beta$-pinene:(+)-3-carene:terpinolene: ethanol & $1: 1: 1: 1: 1$ & $7.14 \pm 1.92 \mathrm{a}$ & $9.60 \pm 1.38 \mathrm{a}$ \\
\hline 15 & Control (none) & NA & $0 \mathrm{~d}$ & $0 \mathrm{~b}$ \\
\hline
\end{tabular}

$N=5$ for each treatment; Means in the same column followed by a different letter are significantly different at a $=0.05$ using the Bonferroni approach.

* The release rate is about $300 \mu \mathrm{L} / \mathrm{d}$.

\subsection{Field trap experiment}

Of the four terpenes tested alone, (+)- $\alpha$-pinene was significantly more attractive to $M$. alternatus (Tab. II). There were no significant differences in trap catches between the other three terpenes, and they caught less than half the number of beetles as the (+)- $\alpha$-pinene baited traps. None of the 10 control traps caught any beetles. All females collected were gravid, with a mean of $10.82 \pm 0.31 \mathrm{eggs} /$ female. There were no significant differences in eggs per female between different treatments.

The blends were less attractive than (+)- $\alpha$-pinene alone. Only one significant difference in trap catch was detected between any of the terpene blends (Tab. II). In the univariate analysis of orthogonal design, the optimal monoterpene blend of (+)- $\alpha$-pinene: (-)- $\beta$-pinene: $(+)$-3-carene: terpinolene was $2: 4: 1: 2$. Moreover, the amount of terpinolene was the most important factor in determining trap catch of the blend, and the optimal amount of terpinolene was two aliquots. The quantitative changes of $(+)$ - $\alpha$-pinene, $(-)-\beta$-pinene and $(+)-3$-carene had no significant effect on trap catch.

The lure with $(+)$ - $\alpha$-pinene $+(-)-\beta$-pinene $+(+)$-3-carene + terpinolene + ethanol in a 1:1:1:1:1 ratio also was attractive to M. alternatus (Tab. II). The trap catch with this blend was not significantly different from that of $(+)$ - $\alpha$-pinene alone. The addition of ethanol to a straight blend of the four terpenes resulted in a beetle catch almost double the number of the blend without ethanol.

\section{DISCUSSION}

Our results indicate that $(+)$ - $\alpha$-pinene can be considered as a primary attractant for $M$. alternatus in China. The amount of $(+)$ - $\alpha$-pinene greatly increased when the pines were stressed, 
suggesting that $(+)$ - $\alpha$-pinene is a critical element for $M$. alternatus in locating a preferred host. Ethanol may also be very important in host selection, as its addition to a monoterpene blend greatly enhanced attraction. Our results reaffirm the conclusion from a previous study that ethanol works as a synergist to host terpene [11]. Further research on the attractiveness of a combination of (+)- $\alpha$-pinene and ethanol as well as the effects of different release rates of these attractants should assist in the development of effective lures.

All of the beetles attracted by these monoterpenes were adults in the oviposition period, as all female beetles were gravid. Moreover, all of the combinations of the four compounds failed to attract the adults in their preoviposition state. Adults of the subfamily Lamiinae in family Cerambycidae usually require a period of maturation feeding before mating [16]. The results suggest that the compounds tested are ineffective for attracting adults during maturation feeding and that other attractants are used by adults in this preoviposition period.

The addition of (-)- $\beta$-pinene, $(+)-3$-carene, and terpinolene decreased the attractiveness of $(+)$ - $\alpha$-pinene. $(+)$-3-carene was one of the compounds that elicited largest EAG responses in M. alternatus (unpublished data). However, the absolute abundance of (+)-3-carene was not significantly different between stressed and healthy stems (Tab. I). These results suggest that (-)- $\beta$-pinene, $(+)$-3-carene, and terpinolene may have value for $M$. alternatus in locating potential hosts (pines), but that (+)$\alpha$-pinene and ethanol may be utilized in landing and host acceptance for oviposition.

The importance of visual cues in host selection behavior has been reported in many phytophagous insects $[2,4,10,19$, 24], and studies have demonstrated that visual cues are used in the host-finding behavior of Cerambycid species [8, 17, 18]. Further studies on how visual cues are utilized in combination with attraction to host volatiles should clarify the host selection precess of $M$. alternatus.

Acknowledgements: We greatly appreciate a thorough review and editing of the manuscript by Drs. Stephen Clarke and Daniel R. Miller, USDA Forest Service. We sincerely thank Drs. Liu Zhudong and Zhang Longwa (Institute of Zoology, Chinese Academy of Sciences) for their helpful comments on the manuscript. Thanks are also extended to Mr. Ma Shengan (Director of Xuancheng Forest protection Station, Anhui) for his assistance in fieldwork. This work was supported by the CAS Knowledge Innovation Program (KSCX1-SW13) and National Natural Science Foundation of china (30525009).

\section{REFERENCES}

[1] Alfaro R.I., Pierce H.D., Borden J.H., Oehlschlager A.C., Role of volatile and nonvolatile components of Sitka spruce bark as feeding stimulants for Pissodes strobi Peck (Coleoptera: Curculionidae), Can. J. Zool. 58 (1980) 626-632.

[2] Aluja M., Prokopy R.J., Host odor and visual stimulus interaction during intratree host finding behavior of Rhagoletis pomonella flies, J. Chem. Ecol. 19 (1993) 2671-2696.

[3] Barata E.N., Pickett J.A., Wadhams L.J., Woodcock C.M., Mustaparta H., Identification of host and non-host semiochemicals of eucalyptus woodborer Phoracantha semipunctata by Gas
Chromatography-Electroantennography, J. Chem. Ecol. 26 (2000) $1877-1895$

[4] Butkewich S.L., Prokopy R.J., Attraction of adult Plum curculios (Coleoptera: Curculionidae) to host-tree odor and visual stimuli in the field, J. Entomol. Sci. 32 (1997) 1-6.

[5] Blight M.M., Pickett J.A., Wadhams L.J., Woodcock C.M., Antennal perception of oilseed rape, Brassica napus (Brassicaceae) volatiles by the cabbage seed weevil Ceutorhynchus assimilis (Coleoptera: Curculionidae), J. Chem. Ecol. 21 (1995) 1649-1664.

[6] Chai X.M., He Z.H., Li C.C., Tang L.F., Cheng S.F., Study on oviposition habit of the Japanese pine sawyer, Monochamus alternatus Hope, J. Beijing For. Univ. 19 (1997) 69-73 (in Chinese).

[7] Chai X.M., Jiang P., Monochamus alternatus, in: Chai X.M., Jiang P. (Eds.), Occurrence and control of pine wilt disease, Chinese Agricultural press, Beijing, 2004, pp. 70-75 (in Chinese).

[8] De Groot P., Nott R., Evaluation of traps of six different designs to capture pine sawyer beetles (Coleoptera: Cerambycidae), Agric. For. Entomol. 3 (2001) 107-111.

[9] Hanula J.L., Berisford C.W., Debarr G.L., Monoterpene oviposition stimulants of Dioryctria amatella in volatiles from fusiform rust galls and second-year loblolly pine cones, J. Chem. Ecol. 11 (1985) 943-952.

[10] Harris M.O., Rose S., Malsch P., The role of vision in the host plantfinding behaviour of the Hessian fly, Physiol. Entomol. 18 (1993) $31-42$.

[11] Ikeda T., Enda N., Yamade A., Oda K., Toyoda T., Attractants for the Japanese pine sawyer, Monochamus alternatus Hope (Coleoptera: Cerambycidae), Appl. Entomol. Zool. 15 (1980) 358361.

[12] Jactel H., Kleinhentz M., Marpeau-Bezard A., Marion-Poll F., Menassieu P., Burban C., Terpene variations in maritime pine constitutive oleoresin related to host tree selection by Dioryctria sylverstella Ratz. (Lepidoptera: Pyralidae), J. Chem. Ecol. 22 (1996) 1037-1050

[13] Kobayashi F., Yamane A., Ikeda T., The Japanese pine sawyer beetles as the vector of pine wilt disease, Ann. Rev. Entomol. 29 (1984) 115-35.

[14] Leather S.R., Pine monoterpenes stimulate oviposition in the pine beauty moth, Panolis flammea, Entomol. Exp. Appl. 43 (1987) 295303.

[15] Li C.X., Wang Z.H., Wang W.L. (Ed.), Biological statistics, 2nd ed., Science Press, Beijing, 2002, pp. 149-156 (in Chinese)

[16] Linsley E.G., The Cerambycidae of North America. Part I. Introduction. University of California Press, Berkeley, Calif. Univ. Calif. Publ. Entomol., 1961, p. 18.

[17] McIntosh R.L., Katinic P.J., Allison J.D., Borden J.H., Downey D.L., Comparative efficacy of five types of trap for woodborers in the Cerambycidae, Buprestidae and Siricidae, Agric. For. Entomol 3 (2001) 113-120.

[18] Morewood W.D., Hein K.E., Katinic P.J., Borden J.H., An improved trap for large wood-boring insects, with special reference to Monochamus scutellatus (Coleoptera: Cerambycidae), Can. J. For. Res. 32 (2002) 519-525.

[19] Prokopy R.J., Owens E.D., Visual detection of plants by herbivorous insects. Ann. Rev. Entomol. 28 (1983) 337-364.

[20] Ross D.W., Birgersson G., Espelie K.E., Berisford C.W., Monoterpene emissions and cuticular lipids of loblolly and slash pines: Potential bases for oviposition preferences of the Nantucket pine tip moth, Can. J. Bot. 73 (1995) 21-25.

[21] Sadof C.S., Grant G.G., Monoterpene composition of Pinus sylvestris varieties resistant and susceptible to Dioryctria zimmermani, J. Chem. Ecol. 23 (1997) 1917-1927.

[22] SPSS Inc., SPSS for Windows, Rel. 11.0.1. SPSS Inc., Chicago, 2001 . 
[23] Sun J.H., Miao Z.W., Zhang Z., Zhang Z.N., Gillette N.C., Red turpentine beetle, Dendroctonus valens LeConte (Coleoptera: Scolytidae), response to host semiochemicals in China, Environ. Entomol. 33 (2004) 206-212.

[24] Szentesi A., Hopkins T.L., Collins R.D., Orientation responses of the grasshopper, Melanoplus sanguinipes, to visual, olfactory and wind stimuli and their combinations, Entomol. Exp. Appl. 80 (1996) 539-549.

[25] Thiery D., Visser J.H., Masking host plant odour in olfactory orientation of the Colorado potato beetle, Entomol. Exp. Appl. 41 (1986) 165-172.

[26] Thiery D., Visser J.H., Misleading the Colorado potato beetle with an odor blend, J. Chem. Ecol. 13 (1987) 1139-1146.

[27] Tiberi R., Niccoli A., Curini M., Epifano F., Marcotullio M.C., Rosati O., The Role of the monoterpene composition in Pinus spp. needles, in host selection by the pine processionary caterpillar, Thaumetopoea pityocampa, Phytoparasitica 27 (1999) 263-272.
[28] Wang Y.Y., Shu C.R., Sun Y.C., A preliminary report on attractants of Monochamus alternatus Hope, Sci. Silv. Sin. 27 (1991) 186-191 (in Chinese).

[29] Yang B.J., Pan H.Y., Tang J., Wang Y.Y., Wang L.F., Vectors of pine wood nematode, in: Yang B.J., Pan H.Y., Tang J., Wang Y.Y., Wang L.F. (Eds.), Bursaphelenchus xylophilus, Chinese Forestry press, Beijing, 2003, pp. 61-62 (in Chinese).

[30] Yang B., Wang Q., Distribution of the pine wood nematode in China and susceptibility of some Chinese and exotic pines to the nematode, Can. J. For. Res. 19 (1989) 1527-1530.

[31] Zhang W.T. (Ed.), Statistics analysis tutorial (Advanced), Beijing Hope Electronic Press, Beijing, 2002, pp. 21-24 (in Chinese).

[32] Zhao Z.D., Xu F.Y., Recent progress of research on relations between pine chemistry and pine wilt disease caused by PWN, Chem. Indust. For. Prod. 18 (1998) 83-88. 